\title{
Cenários Prospectivos como Ferramenta de Gestão para as Instituições de Ensino Superior
}

\section{Prospective Scenarios as a Management Tool for Higher Education Institutions}

\author{
Welton Roberto Silva ${ }^{1}$ \\ Alfredo José Machado Neto ${ }^{2}$ \\ José Alfredo de Pádua Guerra ${ }^{3}$
}

\begin{abstract}
Resumo
O presente estudo tem por objetivo analisar a aplicação de cenários prospectivos em uma Instituição Municipal de Ensino Superior (IMES), em um espaço temporal de cinco anos (2018-2022), e comparar ao estudo similar desenvolvido para os cinco anos anteriores (2014-2018) a fim de identificar prováveis ameaças e oportunidades no segmento estudado. A pesquisa foi fundamentada em estudos sobre cenários prospectivos. Para a elaboração de cenários prospectivos foi utilizado o método Delphi. A coleta de dados foi realizada com o uso de questionário aplicado a profissionais que atuam em Instituição de Ensino Superior. Foi realizado um estudo de caso longitudinal e comparativo com uma abordagem quali-quantitativa dos dados. Como resultado, foi possível construir três cenários: otimista, pessimista e realista, que servirão de base para o planejamento estratégico da IMES. A comparação ao estudo realizado em 2014 mostrou que algumas das variáveis presentes naquela prospecção também aparecem na atual. A pesquisa contribui para os estudos sobre administração estratégica das Instituições de Ensino Superior e oferece uma contribuição prática para o planejamento dessas organizações: a construção de cenários e a análise de probabilidades de cenários futuros para as organizações de ensino. Também oferece uma contribuição prática para outras Instituições de Ensino Superior da região pesquisada.

Palavras-chave: Estratégia organizacional. Prospecção de cenários. Administração estratégica. Instituições do Ensino Superior.
\end{abstract}

\begin{abstract}
The present study aims to analyze the application of prospective scenarios in a Municipal Higher Education Institution (MHEI) over a five-year period (2018-2022) and to compare it to a similar study developed for the previous five years (2014-2018) in order to identify probable threats and opportunities in the studied segment. The research was grounded on
\end{abstract}

1 Centro Universitário Municipal de Franca - Uni-FACEF, Brasil. ORCID: http://orcid.org/0000-0002-5994-4263 E-mail: welton@facef.br.

2 Centro Universitário Municipal de Franca - Uni-FACEF, Brasil. ORCID: http://orcid.org/0000-0001-5312-0856 E-mail: alfredo@facef.br

3 Centro Universitário Municipal de Franca - Uni-FACEF, Brasil.

ORCID: http://orcid.org/0000-0001-7234-8127 E-mail: josealfredopaduaguerra@gmail.com 
studies on prospective scenarios. The Delphi Method was used for preparing the prospective scenarios. Data were collected by using a questionnaire applied to professionals who work in Higher Education Institutions. A longitudinal and comparative case study was carried out by using data quali-quantitative approach. As a result, it was possible to build three scenarios: optimistic, pessimistic and realistic ones which will serve as the basis for the MHEI strategic planning. The comparison to the study accomplished in 2014 showed that some of the present variables in that prospection also appear in the current one. The research contributed to the studies on the strategic administration of Higher Education Institutions and offers a practical contribution to the planning of these organizations: the construction of scenarios and the analysis of the probabilities of future scenarios for the educational organizations. It also offers a practical contribution to other Higher Education Institutions in the researched region.

Keywords: Organizational strategy. Scenario prospection. Strategic management. Higher Education Institutions.

$* * *$

\section{Introdução}

Mudanças ambientais são, de forma geral, fonte de preocupações para gestores e para tomadores de decisões, especialmente em um contexto de grande evolução tecnológica. Transformações econômicas, políticas, sociais, culturais, dentre tantas outras, ocasionaram alterações no perfil das populações, lançando, assim, novos desafios para a resolução dos problemas e a assimilação das oportunidades.

A relação entre a ação organizacional e o macroambiente sempre foi marcada por eventos capazes de influenciar e, por vezes, colocar em cheque estratégias cuidadosamente formuladas para o desenvolvimento organizacional de médio e longo prazo. Em vista disto, gestores buscam estabelecer planos para que forças externas não minem o trabalho, até então, desenvolvido.

A evolução tecnológica forneceu às organizações e aos seus gestores novas ferramentas úteis ao gerenciamento organizacional; entretanto, levou este ambiente a uma instabilidade até então desconhecida, e por vezes não identificada, mas mesmo assim existente (Kotler \& Caslione, 2009). Lastres (1999) descreve este novo momento como a Era do Conhecimento, 
responsável não apenas pelo surgimento da incerteza ambiental, mas também pela reformulação do modo de vida das pessoas.

A compreensão dos gestores das oportunidades para as organizações pode gerar ações em busca de vantagens competitivas. Esse conhecimento possibilita que as organizações possam se preparar para possíveis problemas e/ou valer-se de potenciais oportunidades. Conforme proposto por Marcial e Grumbach (2002, p. 33), "o ritmo acelerado das mudanças políticas, econômicas, sociais e tecnológicas no mundo tem, como consequência, frequentes rupturas de tendências. Essas rupturas aumentam a incerteza com relação ao futuro . ... As rupturas, descritas pelos autores, provocam incertezas, alteram o ritmo de mudanças e fazem com que os gestores enfrentem dificuldades para lidar com o amanhã.

O objetivo do presente artigo é analisar cenários prospectivos para uma Instituição Municipal de Educação Superior (IMES), do interior do Estado de São Paulo, Brasil, em um espaço temporal de cinco anos (20182022), e comparar ao estudo similar desenvolvido para os cinco anos anteriores (2014-2018). Além do objetivo geral, essa pesquisa buscou alcançar os seguintes objetivos específicos: (1) identificar pontos de ruptura no ambiente de negócios do setor educacional de nível superior da região estudada; (2) fornecer subsídios para que a IES pesquisada possa fundamentar seu planejamento estratégico.

O estudo se justifica pela necessidade de contribuições práticas para o segmento alvo da pesquisa, com informações sobre probabilidades de futuros para organizações de ensino. Tal como os demais setores da economia, as empresas do setor educacional se encontram em um ambiente de negócios extremamente competitivo, com uma tendência de concentração, a partir de fusões e aquisições de instituições menores pelos grandes grupos educacionais. Além disso, o crescimento da modalidade EAD (Educação a Distância) e do regime semipresencial, com a inclusão de um percentual de aulas ministradas fora da sala de aula, são fatores que tendem a acirrar a concorrência no setor. 
A pesquisa foi conduzida por abordagens metodológicas qualitativa e quantitativa. A fundamentação teórica foi realizada a partir de estudos sobre cenários prospectivos e estudos sobre o ensino superior. Em seguida, foram construídos e analisados três cenários prospectivos para o Centro Universitário Municipal de Franca - Uni-FACEF, tendo como base o método de Blanning e Reinig (1998). Estes cenários foram comparados aos construídos em um estudo similar efetuado em 2014. Em conclusão, foram sugeridas algumas ações estratégicas para a IES para o horizonte de 2018/2022.

\section{A Ação Organizacional e os Fatores do Macro Ambiente}

A tomada de decisões é vista, ao longo da história, como um processo que demanda precisão e análise de circunstâncias ambientais específicas de cada organização, especialmente se considerar que os gestores têm se deparado com um ambiente organizacional marcado por instabilidades. Tais incertezas tornam o ambiente organizacional vulnerável, especialmente quando consideradas as constantes inovações tecnológicas e seu impacto na geração e difusão da informação.

Se, no passado, uma determinada notícia levava alguns dias para que seu destinatário final a soubesse, desde os últimos anos do século XX, vivenciou-se um ser humano completamente conectado, e livre daquela condição de isolamento, que limitava sua rede de contato imediata a pequenas distâncias. Tal quadro tornou-se ainda mais intenso após a ascensão das redes sociais, especialmente a partir da primeira década do século vigente. Kotler e Caslione (2009, p. 3) afirmam que "a velocidade da mudança e a magnitude dos choques são maiores do que nunca"; diferentemente do passado, "essa é a nova normalidade. Vai além das inovações disruptivas e abrange novos choques".

Como consequência, o ambiente de negócios passou a apresentar quebras de tendência e pontos de ruptura (breakpoints), que, para Strebel 
(1993, p. 24), são fatores que propiciam "alterações quantitativas nas regras do jogo da indústria ou da empresa . ..”.

No Brasil, tal situação passou a ser observada principalmente no final do século XX, momento em que o país ainda sofria reflexos da decadência do Milagre Econômico dos anos 1970. Naquela época, vivenciou-se a abertura da economia brasileira, seguida de perto pela reestruturação econômica, controle inflacionário e paridade cambial, advindos do Plano Real. Tornou-se nítido o despreparo geral dos empreendimentos nacionais (Mancuso \& Oliveira, 2006). O país passou por períodos de estabilidade econômica no final dos anos 1990 e no princípio do século XXI, ocasionados, principalmente, pelos desdobramentos das medidas adotadas durante o Plano Real, somadas às políticas de inclusão de parte da população em ciclos de consumo, a partir da expansão do crédito e Programas de Distribuição de Renda (Gremaud, Vasconcelos, \& Toneto Júnior, 2007).

Entretanto, o quadro econômico brasileiro apresentou um profundo declínio a partir de 2014, com quedas crescentes de investimentos e elevação nas taxas de desemprego, além da retração no PIB ocorrida a partir de 2015 (Pinto et al, 2016). Os autores discorrem, ainda, sobre o fato de não haver divisão entre a crise econômica enfrentada pelo país e a crise política que se desenvolve em torno do Governo.

Por fim, considera-se que, no ano 2018, com a ocorrência de um processo eleitoral no país, gerou-se instabilidade política, que se vinculou à instabilidade econômica, ocasionando mais insegurança para os investidores e, consequentemente, um agravamento da crise político-econômica. Assim sendo, estudos que possibilitam o mapeamento do ambiente de negócios, bem como suas perspectivas para os próximos anos, se tornam de grande valia, uma vez que viabilizam a prática organizacional a partir do entendimento de variáveis micro e macro ambientais. 


\section{Cenários Prospectivos}

Dentre as técnicas de análise de probabilidades de futuros, o estudo de cenários prospectivos surge, objetivando sanar as lacunas presentes na formulação da estratégia competitiva das organizações e minimizar a incerteza ambiental. Neste campo, Porter (1989, p. 411 e 412) afirma:

... toda empresa lida de algum modo com a incerteza. Porém normalmente ela não é abordada de um modo adequado na formulação da estratégia competitiva. As estratégias são frequentemente baseadas na suposição de que o passado irá repetir-se ou nas previsões implícitas dos próprios gerentes quanto ao futuro mais provável . . . Com a maior necessidade de uma abordagem explicita da incerteza no planejamento, algumas empresas começaram a utilizar cenários como instrumentos para que pudessem compreender as implicações estratégicas da incerteza de um modo mais completo.

O estudo de cenários tem por base a prospecção de eventos ou variáveis que possam impactar um empreendimento em um determinado espaço de tempo (Schwartz, 2003). Em síntese, trata-se de um procedimento sistemático que orienta a identificação de possíveis tendências que o ambiente organizacional pode vir a assumir dentro de um espaço determinado de tempo, bem como as forças que podem ocasionar alterações neste ambiente. Isto permite, também, pensar no planejamento de ações estratégicas para cada cenário desenvolvido (Ratter, 1979).

Porter (2004, p. 243) sintetiza o conceito enunciando-o como "visões parciais e internamente consistentes de como o mundo será no futuro e que podem ser escolhidas de modo a limitar o conjunto de circunstâncias que podem vir a ocorrer". Tal argumentação mostra a importância do estudo, bem como a sua aplicação no ambiente de negócios.

Ao se considerar o trabalho com cenários prospectivos, faz-se uso de uma ferramenta que permite a compreensão do ambiente incerto no qual as organizações caminham em tempos de elevado desenvolvimento tecnológico e de globalização da concorrência. A construção de cenários prospectivos atenua o grau de incertezas pelo fato dessa metodologia considerar eventos 
atuais com implicações futuras, com incidência no médio e longo prazo (Schwartz, 2006).

As organizações aqui estudadas vêm passando por profundas alterações, com uma tendência à concentração do setor e com novas Instituições de Ensino Superior entrando no mercado, com especial destaque às que trabalham com a Educação à Distância (EAD), segmento que ganhou destaque nos últimos anos em decorrência da facilidade de acesso, além de possuir preços mais acessíveis.

\section{Uma Instituição do Ensino Superior no Brasil: Uni-FACEF}

O foco do presente estudo se encontra no Ensino Superior, segmento que experimentou forte crescimento nos últimos anos, especialmente motivado pelo desenvolvimento tecnológico cada vez mais intenso. Por se tratar de um setor que se encontra em expansão, é possível perceber a incidência de pontos de rupturas, ou seja, eventos que causam interferência nos planos estratégicos das instituições, como por exemplo: fusões ou parcerias entre IES, a aquisição de uma instituição por outra ou por grupos educacionais, abertura de capital de conglomerados do ensino superior, ingresso de instituições internacionais com participação no capital de IES já existentes ou mesmo com a entrada direta no mercado nacional (Silva; Machado Neto, 2014). Desta forma, percebe-se que o ambiente, no qual se inserem as organizações objeto deste estudo, sofreu mudanças que impactaram diretamente sua gestão.

Outro aspecto a ser destacado se refere à regulamentação exercida pelo Ministério da Educação a fim de garantir uma maior qualidade nos cursos oferecidos à população. Neste sentido, o que se observa é que; com a sanção da lei 10.861 de 2004, que cria e regulamenta o Sistema Nacional de Avaliação da Educação Superior (SINAES), há a implantação de novos dispositivos de controle de desempenho dos cursos, com base principal no ENADE (Exame Nacional de Desempenho dos Estudantes do Ensino Superior), gerando indicadores tais como: o Conceito ENADE, o Indicador de 
Diferença entre o Desempenho Observado e o Esperado (IDD), o Conceito Preliminar de Curso (CPC), o Conceito de Curso (CC), o Índice Geral de Curso (IGC) e o Conceito Institucional (CI). De forma geral, este fato vem provocando turbulência com relação à forma de estabelecer as diretrizes para o planejamento.

Por fim, destaca-se o objeto de estudo, o Centro Universitário Municipal de Franca - Uni-FACEF, fundado em 1951 como uma instituição privada, teve inicialmente seu vínculo com o Instituto Francano de Ensino. Sua encampação pelo poder público local se deu por meio de um projeto de lei do vereador Bernardino Pucci em 1966, finalizada pela Lei $n^{\circ}$. 1452/66. Seu primeiro diretor foi o professor Alfredo Palermo, que contemplou sua primeira turma, formada no curso de Ciências Econômicas em 1954 (Oliveira et.al., 2011).

Em 2004, após processo de avaliação do Conselho Estadual de Educação de São Paulo (CCE/SP), passou à categoria de Centro Universitário, podendo, assim, ampliar seu portfólio de cursos dos 4 (em vigor à época) para 16 (em 2019). Em 2019, o Uni-FACEF possui três unidades utilizadas para o desenvolvimento de suas atividades, de modo que a IES passou a pautar o seu planejamento "em busca de uma inserção na comunidade local, com vistas à produção de conhecimento que garanta apoio à população, mediante a oferta de serviços de ensino, pesquisa e extensão de qualidade" (Silva, 2013).

\section{Procedimentos Metodológicos}

A presente pesquisa busca conhecer o ambiente de abrangência do objeto aqui tratado, a fim de que os resultados expressem a realidade estudada. Para tanto, optou-se por uma abordagem mista na definição do método: qualitativo e quantitativo, que Duarte (2009) chama de triangulação, ou seja, o uso de duas técnicas de pesquisa para se chegar a um terceiro ponto. Trata-se de uma pesquisa aplicada, ou seja, um estudo que objetiva "gerar conhecimentos para aplicação prática, dirigidos à solução 
de problemas específicos. Envolve verdades e interesses locais" (Moresi, 2003, p. 8). Um estudo de caso comparativo e longitudinal.

Para a prospecção de cenários futuros, o presente estudo fará uso do modelo proposto por Blanning e Reinig (1998).

. . . um método estruturado de avaliação das variáveis nos
cenários esboçados e discutem sua implementação através de
um caso. Os autores sugerem que se faça uma lista de
eventos indicando-se a probabilidade de ocorrência destes
eventos, obtida a partir da votação por um grupo de
participantes do processo. Em seguida é construída uma
matriz de eventos, em que, no eixo horizontal, tem-se a
probabilidade do evento (P) e, no eixo vertical, o quanto o
evento é favorável ou desfavorável (F) para a organização ou
a empresa que está desenvolvendo a análise (Almeida,
Onusic \& Machado Neto, 2005, p. 5).

Para a coleta de dados, o público pesquisado foi composto de professores e dirigentes da Instituição de Ensino Superior, por meio da utilização de formulários. A coleta de dados foi conduzida pelo Método Delphi que é um processo de comunicação em grupo, com a preservação do anonimato, baseado em sucessivas rodadas de questionários, o que garante equilíbrio e estabilidade nas respostas (Linstone \& Turoff, 2011). Como resultado, o método permite a elaboração de três cenários distintos, que são classificados como: otimista, pessimista e realista.

\section{Apresentação e Análise dos Resultados da Pesquisa}

O objetivo do presente estudo foi analisar cenários prospectivos para uma Instituição Municipal de Ensino Superior em um espaço temporal de cinco anos (2018-2022), além de compará-lo ao estudo similar desenvolvido para os cinco anos anteriores (2014-2018) a fim de identificar ameaças e oportunidades no segmento estudado. 


\subsection{Prospecção de Cenários para o Uni-FACEF - 2018/2022}

A Tabela 1 apresenta a Matriz de Probabilidade e Favorabilidade, com os eventos levantados na pesquisa, por meio da aplicação de questionários.

Tabela 1. Matriz de Probabilidade e Favorabilidade: Cenários Uni-FACEF 2018-2022

\begin{tabular}{l|l|c||c}
\multicolumn{2}{c|}{ Descrição } & Prob. & Fav. \\
\hline \hline Evento 01 & Aumento da concorrência entre IES em Franca e na região & 7,3 & 3,8 \\
\hline \hline Evento 02 & Aumento da oferta e da concorrência dos cursos EAD & 8,1 & 2,7 \\
\hline \hline Evento 03 & Redução da oferta de bolsas do PROUNI & 5,6 & 5,5 \\
\hline \hline Evento 04 & Redução da oferta de financiamentos do FIES & 7,6 & 1,8 \\
\hline \hline Evento 05 & Aumento do Financiamento Estudantil privado & 7,5 & 4,8 \\
\hline \hline Evento 06 & Aumento na exigência por um ensino superior de qualidade & 7,3 & 7,2 \\
\hline \hline Evento 07 & Novos convênios acadêmicos internacionais & 7,7 & 7,9 \\
\hline \hline Evento 08 & Baixa qualidade na formação escolar pré-universitária & 9,1 & 1,8 \\
\hline \hline Evento 09 & Infraestrutura e tecnologias adequadas & 8,8 & 7,7 \\
\hline \hline Evento 10 & Oferta de novos cursos & 8,3 & 6,6 \\
\hline \hline Evento 11 & Baixa procura por cursos tradicionais da IES & 7,7 & 1,9 \\
\hline \hline Evento 12 & Alteração na pirâmide etária & 8,5 & 4,0 \\
\hline \hline Evento 13 & Redes e parcerias focadas & 7,6 & 8,4 \\
\hline \hline Evento 14 & Intervenção do município na gestão das IES municipais & 4,3 & 1,5 \\
\hline \hline Evento 15 & Criação de um polo tecnológico na cidade & 5,7 & 7,9 \\
\hline \hline Evento 16 & Diversificação da economia local & 5,2 & 8,2 \\
\hline \hline Evento 17 & Instabilidade política nacional & 7,5 & 2,3 \\
\hline \hline Evento 18 & Queda do desemprego & 5,3 & 5,7 \\
\hline \hline Evento 19 & Redução da renda per capita do brasileiro & 5,5 & 1,8 \\
\hline \hline Evento 20 & Plataformas on-line de dados e informações & 6,6 \\
\hline \hline
\end{tabular}

O modelo de Blanning e Reinig (1998) pressupõe a elaboração de três cenários, sendo que cada qual abriga uma quantidade de eventos de acordo com sua Probabilidade e Favorabilidade. Os cenários são dispostos em um plano cartesiano, composto pelos eixos $X$ (dimensionador de Probabilidade) e $Y$ (dimensionador de Favorabilidade).

O cenário otimista é composto por eventos que apresentam elevada probabilidade de ocorrência e que são favoráveis para a IES. O cenário pessimista é constituído por eventos com grande probabilidade de ocorrência e que são desfavoráveis para a IES. Já o cenário realista congrega os eventos 
que apresentam uma maior probabilidade de virem a ocorrer, favoráveis ou desfavoráveis para a IES.

A Figura 1 apresenta os resultados do estudo, com a construção de três cenários (otimista, pessimista e realista), para o Uni-FACEF - Centro Universitário Municipal de Franca, para o período de 2018 a 2022.

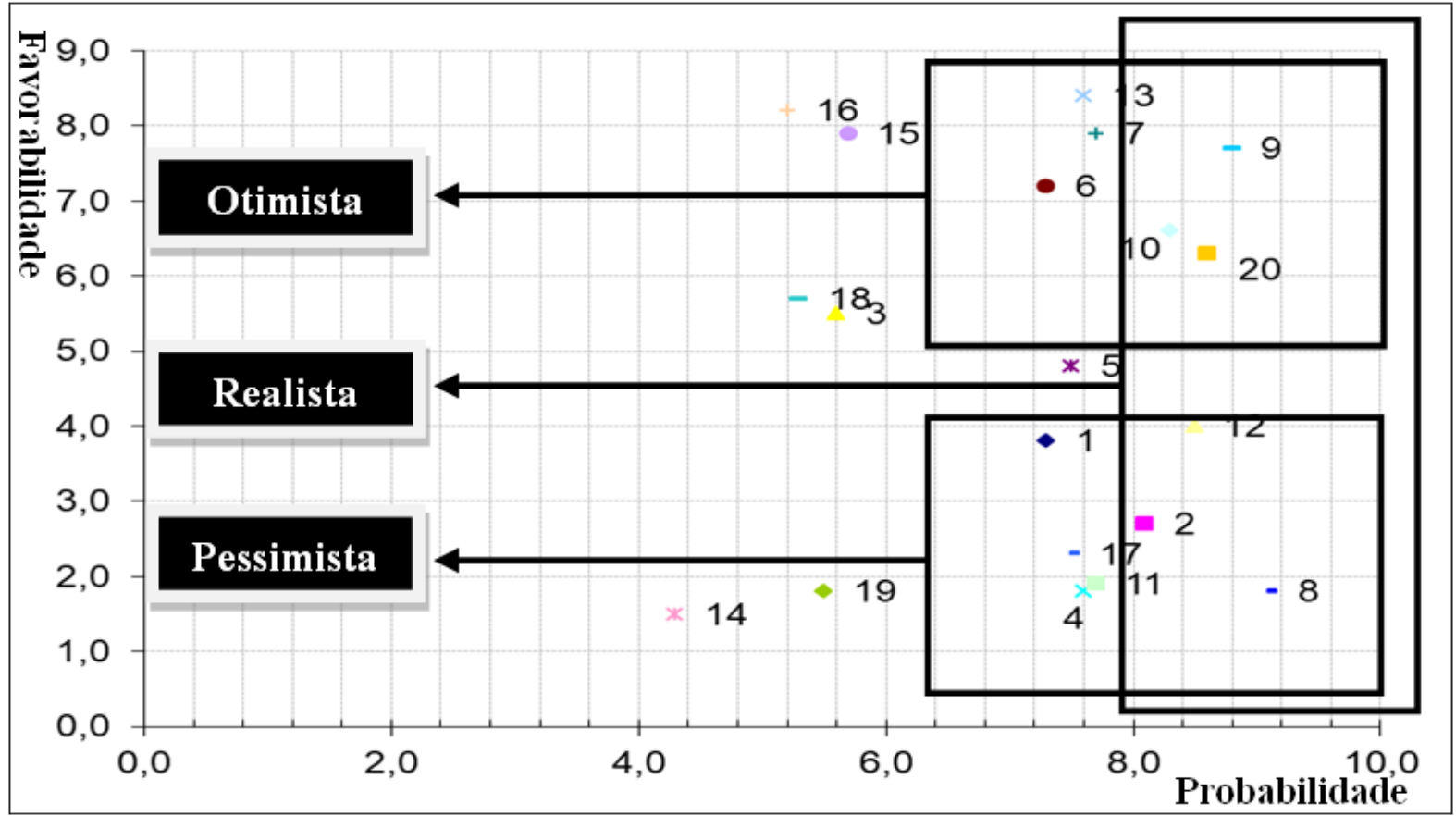

Figura 1. Cenários prospectivos para o Uni-FACEF 2018/2022

O cenário otimista é composto por seis eventos que apresentam elevada probabilidade de virem a ocorrer (acima de $70 \%$ ) e que são favoráveis para a/as IES: Evento Seis (6) - Aumento na exigência por um ensino superior de qualidade; Evento Sete (7) - Novos convênios acadêmicos internacionais; Evento Nove (9) - Infraestrutura e tecnologias adequadas; Evento Dez (10) - Oferta de novos cursos; Evento Treze (13) - Redes e parcerias focadas; e Evento Vinte (20) - Plataformas on-line de dados e de informações.

Já o cenário pessimista registrou sete eventos que apresentam grande probabilidade de virem a ocorrer (acima de 70\%) e que são desfavoráveis para a IES: Evento Um (1) - Aumento da concorrência entre IES em Franca e na região; Evento Dois (2) - Aumento da oferta e 
concorrência dos cursos EAD; Evento Quatro (4) - Redução da oferta de financiamentos do FIES; Evento Oito (8) - Baixa qualidade na formação escolar pré-universitária; Evento Onze (11) - Baixa procura por cursos tradicionais da IES; Evento Doze (12) - Alteração na pirâmide etária; e Evento Dezessete (17) - Instabilidade política nacional.

Por sua, vez o cenário realista é composto por seis eventos com graus mais elevados de probabilidade de virem a ocorrer (acima de 80\%), sendo três eventos favoráveis para a IES (Evento Nove (9) - Infraestrutura e tecnologias adequadas; Evento Dez (10) - Oferta de novos cursos; e Evento Vinte (20) - Plataformas on-line de dados e de informações), e três eventos desfavoráveis para a IES (Evento Dois (2) - Aumento da oferta e concorrência dos cursos EAD; Evento Oito (8) - Baixa qualidade na formação escolar pré-universitária; e Evento Doze (12) - Alteração na pirâmide etária).

\subsection{Análise Comparativa dos Cenários para 2014/2018 e 2018/2022}

As Tabelas 2, 3 e 4, apresentadas a seguir, permitem comparar os eventos que compuseram os três cenários da prospecção atual com os constantes dos cenários do estudo realizado no ano de 2014.

Tabela 2. Uni-FACEF - Cenários Otimistas em 2014/2018 e 2018/2022

\begin{tabular}{|c|c|}
\hline $\begin{array}{c}\text { Eventos do cenário otimista } \\
2014 / 2018\end{array}$ & $\begin{array}{c}\text { Eventos do cenário otimista } \\
2018 / 2022\end{array}$ \\
\hline $\begin{array}{l}\text { - } \\
\text { Aumento de recursos públicos e } \\
\text { privados para pesquisas } \\
\text { tecnológicas. } \\
\text { - Escassez de profissionais de nível } \\
\text { superior em determinadas áreas do } \\
\text { mercado. } \\
\text { Invest. governo em bolsas no } \\
\text { exterior, aumento de intercâmbio de } \\
\text { estudantes e pesquisadores. } \\
\text { Estabelecimento de parcerias } \\
\text { regionais de incentivo e de } \\
\text { desenvolvimento do turismo } \\
\text { regional. } \\
\text { Melhoria nas condições do FIES. }\end{array}$ & $\begin{array}{ll}\text { - } & \text { Plataformas on-line de dados e } \\
\text { informações } \\
\text { - Oferta de novos cursos } \\
\text { - Novos convênios acadêmicos } \\
\text { internacionais } \\
\text { - Novos convênios acadêmicos } \\
\text { internacionais } \\
\text { - Redes e parcerias focadas } \\
\text { - Infraestrutura e tecnologias } \\
\text { adequadas } \\
\text { - Aumento na exigência por um } \\
\text { ensino superior de qualidade }\end{array}$ \\
\hline
\end{tabular}


Como se pode verificar na Tabela 2, acima, diversos eventos que compuseram o cenário otimista para o período de 2014 a 2018 se repetiram, talvez com foco um pouco diferente, no cenário otimista para o período de 2018 a 2022.

Assim, a possibilidade de um aumento dos recursos para pesquisas tecnológicas, presente no primeiro, se reflete nos investimentos efetuados pela própria IES, que permitiram a ocorrência e o destaque de dois eventos no cenário atual: Plataformas on-line de dados e de informações e Infraestrutura e tecnologias adequadas.

A constatação, em 2014, da "Escassez de profissionais de nível superior em determinadas áreas do mercado", se reflete, no cenário atual, na "Oferta de novos cursos", que tem sido realizada pela IES, em especial nas áreas da Saúde (Medicina e Enfermagem), Engenharia (Civil e de Produção) e Tecnologia (Engenharia de Software e Ciência da Computação).

A expectativa referente ao aumento de recursos do governo para bolsas no exterior não se concretizou; no entanto, a IES tem investido na formatação de convênios de cooperação com universidades estrangeiras, tendo intensificado o intercâmbio de alunos e docentes com as universidades de Valladolid e Málaga (Espanha) e a Universidade do Porto (Portugal), além de uma participação efetiva no IFBAE - Instituto Franco-Brasileiro de Administração de Empresas. Referido instituto é composto por cinco universidades francesas (Grenoble, Aix-em-Provence, Tours, Poitiers e Rennes) e cinco IES brasileiras (USP, UFRGS, UFMG, UFU e Uni-FACEF) e realiza congressos bienais, além de intercâmbio de discentes, de docentes e de pesquisadores.

Os dois últimos eventos do cenário otimista de 2014, "Estabelecimento de parcerias regionais de incentivo e desenvolvimento do turismo regional" e "Melhorias das condições do FIES", não se concretizaram, sendo que, no caso do FIES, ocorreu exatamente o inverso; as condições do financiamento e a exigência do Governo de uma responsabilidade solidária da IES, em caso de 
inadimplência nos financiamentos, fez com que o Uni-FACEF deixasse de celebrar novos contratos deste financiamento estudantil.

Com relação ao evento "Redes e parcerias focadas", constante da prospeç̧ão atual, a IES tem participado de forma muito ativa da AIMES Associação das Instituições Municipais de Ensino Superior do Estado de São Paulo e ajudou a fundar a ANIMES - Associação Nacional das Instituições Municipais de Ensino Superior, entidades criadas para amparar os pleitos das IES Municipais junto aos órgãos governamentais e promover ações conjuntas para os seus associados. O Uni-FACEF é associado, ainda, da ABRUEM - Associação Brasileira de Reitores de Universidades Estaduais e Municipais.

Quanto ao evento "Exigência de ensino superior de qualidade", a instituição tem incentivado a qualificação de seus professores e funcionários e investido fortemente em sua infraestrutura física, adquirindo equipamentos de última geração para os seus laboratórios, como forma de melhorar continuamente a qualidade dos serviços prestados aos seus clientes.

Tabela 3. Uni-FACEF - Cenários Pessimistas em 2014/2018 e 2018/2022

Eventos do cenário pessimista para 2014/2018
Eventos do cenário pessimista para 2018/2022
- Venda da Unifran para um Grupo Educacional Maior.

- Aumento na Demanda por Cursos EAD.

- Redução no nível de formação escolar dos ingressantes do ensino superior.

- Baixo Crescimento da Economia Nacional.

- Aumento no Custo de Vida.
- Aumento da concorrência entre IES em Franca e na região

- Aumento da oferta e da concorrência dos cursos EAD

- Baixa qualidade na formação escolar pré-universitária

- Instabilidade política nacional

- Baixa procura por cursos tradicionais da IES

- Alteração na pirâmide etária

- Redução da oferta de financiamentos do FIES 
O primeiro evento da prospecção de cenários de 2014, se efetivou com a venda da Unifran - Universidade de Franca, nossa maior concorrente na cidade, para o grupo educacional Cruzeiro do Sul, que tem imprimido uma política de vendas mais agressiva do que os proprietários anteriores. Este comportamento se reflete no primeiro evento da prospecção de cenários atual, ou seja, o "Aumento da concorrência entre IES em Franca e na região".

Os dois eventos seguintes estão presentes nos dois cenários e se referem ao aumento da oferta de cursos $\mathrm{EAD}$ e à baixa qualidade na formação escolar pré-universitária, que tem levado a IES a implementar, para os seus ingressantes em seus cursos, aulas de reforço em disciplinas como Português e Matemática.

O "baixo crescimento da economia nacional" e o "aumento do custo de vida", presentes na prospecção de 2014, são reflexos da "instabilidade política nacional", que consta da prospecção atual; cenário que, espera-se, deve se reverter com o encerramento do processo eleitoral de 2018.

O citado "aumento do custo de vida" (2014), associado à "alteração da pirâmide etária" (envelhecimento da população) e à "redução da oferta de financiamentos do FIES" (2018), são, provavelmente, causas da "baixa procura por cursos tradicionais da IES", evento que consta da prospecção atual.

Como mostra a Tabela 4, alguns eventos que compunham o cenário realista, na prospecção realizada em 2014, também estão presentes no estudo atual e foram comentados nas análises anteriores.

Na prospecção realizada em 2014, o cenário realista era composto por três eventos desfavoráveis para a IES (grifados em amarelo), dois eventos eram considerados favoráveis à instituição (grifados em azul) e dois eventos participavam apenas deste cenário: "Crescimento da população idosa" e "Alteração no perfil do aluno (Geração Y)". Considerou-se, à época, que eram eventos neutros, situações que exigiam apenas uma adaptação por parte da IES. 
Tabela 4. Uni-FACEF - Cenários Realistas em 2014/2018 e 2018/2022

\begin{tabular}{|c|c|}
\hline $\begin{array}{c}\text { Eventos do cenário realista para } \\
\qquad 2014 / 2018\end{array}$ & $\begin{array}{c}\text { Eventos do cenário realista para } \\
2018 / 2022\end{array}$ \\
\hline 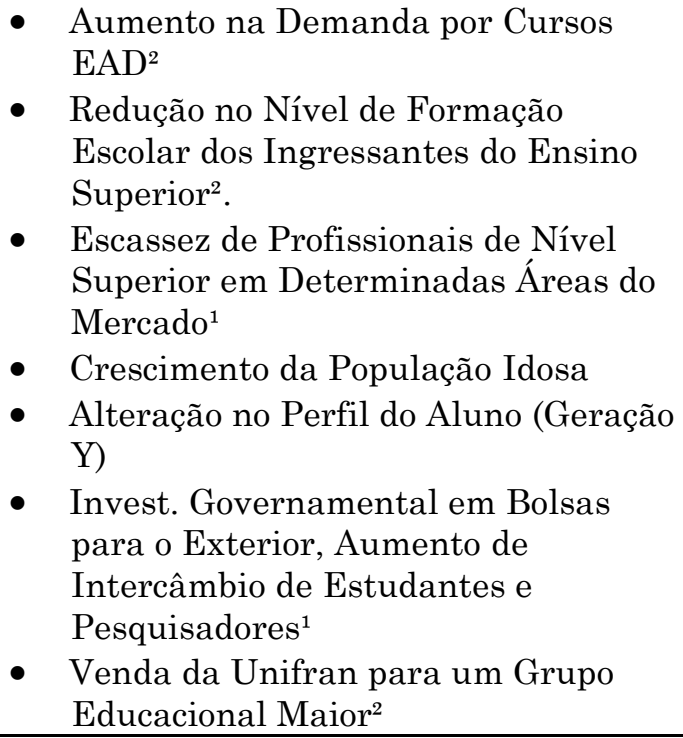 & 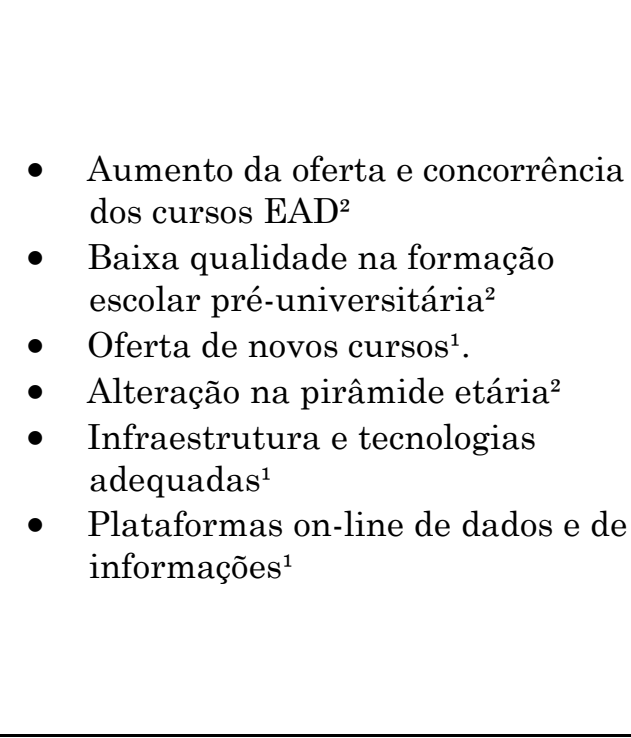 \\
\hline
\end{tabular}

${ }^{1}$ Eventos pertencentes ao cenário otimista

${ }^{2}$ Eventos pertencentes ao cenário pessimista

Na prospecção atual, o cenário realista é composto por três eventos que fazem parte, também, do cenário otimista (grifados em azul) e três eventos compõem, também, o cenário pessimista (grifados em amarelo) e foram analisados anteriormente.

\section{Implicações da Pesquisa e Considerações Finais}

O presente estudo teve por objetivo geral analisar cenários prospectivos para uma Instituição Municipal de Ensino Superior em um espaço temporal de cinco anos (2018-2022), além de compará-lo com o estudo similar desenvolvido para os cinco anos anteriores (2014-2018), a fim de identificar ameaças e oportunidades no segmento estudado.

A pesquisa realizada permitiu a construção dos três Cenários propostos nos mesmos critérios dos elaborados em 2014, o que permitiu comparações. Com relação aos Cenários elaborados na pesquisa atual, o que se pode considerar é que $30 \%$ dos eventos são considerados Otimistas por 
sua favorabilidade, assim como $35 \%$ são analisados como pessimistas. Já o cenário realista congregou $70 \%$ dos eventos levantados, sendo que apenas o "Aumento do financiamento estudantil privado" não foi considerado como favorável ou desfavorável.

O levantamento realizado em 2014 trouxe 25\% dos eventos classificados como otimistas, a mesma quantidade do observado no cenário pessimista. Já o cenário realista abrangeu 35\% dos eventos levantados, estando dois deles ausentes dos outros dois cenários.

Também deve ser considerado que dentre os sete eventos pertencentes ao cenário realista, na pesquisa de 2014, quatro voltam a figurar na pesquisa atual; três deles ainda com alta probabilidade de incidência: aumento na demanda por cursos na modalidade EAD, crescimento da população idosa (alteração na pirâmide etária) e baixa qualidade na formação escolar pré-universitária.

Já o evento venda da Unifran para um grupo educacional maior se concretizou, o que confirma o motivo de ser, à época, o evento de maior probabilidade $(9,60)$. Ainda, alteração no perfil do aluno e escassez de profissionais de nível superior em determinadas áreas do mercado não foram lembrados pela maioria dos respondentes na pesquisa atual.

É importante ressaltar que o levantamento proporcionou à IES estudada subsídios importantes para o seu planejamento estratégico. A IES deverá observar um conjunto de ações para a antecipar a ocorrência de eventos mais favoráveis e se prevenir de possíveis danos daqueles que aparecem como desfavoráveis, como as relacionadas a seguir:

1) Aumento da oferta e da concorrência dos cursos EAD:

a) reforçar a identidade de "única IES local" e aumentar o sentimento de "pertencimento";

b) divulgar, de forma massiva, o diferencial de ensino presencial e integral;

c) reduzir os custos e estabilizar as mensalidades (energia solar, p.ex.). 
2) Aumento do financiamento estudantil privado:

a) realizar gestões junto ao MEC, por intermédio da AIMES, para melhorar condições do FIES;

b) renovar a atuação da AIMES para obtenção de bolsas do PROUNI para as IES municipais;

c) estudar prazos diferentes para o pagamento das mensalidades (ex. pagar os 4 anos em 6 anos).

3) Baixa procura por cursos tradicionais da IES:

a) buscar a melhoria contínua da qualificação dos docentes e dos processos de ensino-aprendizagem;

b) implementar, na medida do possível, metodologias ativas nos cursos tradicionais da IES;

c) incluir "aulas de reforço", gratuitas, em horários alternativos e aos finais de semana.

4) Novos convênios acadêmicos internacionais:

a) aproveitar as viagens da ABRUEM para firmar convênios com IES dos países visitados;

b) ingressar em associações de universidades da América do Sul (convênios USCS);

c) ampliar relações com IES associadas do IFBAE (pós-doc, intercâmbio de alunos e professores).

5) Plataformas on-line de dados e de informações:

a) incentivar alunos da área de TI a desenvolverem "soluções" para a nossa IES;

b) investir em "canais virtuais" de divulgação de nossos cursos, novidades e realizações.

6) Alteração na pirâmide etária:

a) oferecer cursos de extensão para a "melhor idade" e preços diferenciados para a graduação;

b) oferecer cursos da Escola Prática de Negócios em outras áreas (por exemplo: agronegócios). 
7) Redes e parcerias focadas:

a) fortalecer os laços com a AIMES, a ABRUEM, o IFBAE e o Santander Universidades;

b) firmar convênios com outras entidades empresariais (Unimed, Hospital Regional etc.)

8) Instabilidade política nacional:

a) acompanhar, atentamente, o desenrolar da crise política nacional e seus reflexos para a IES;

b) estudar medidas preventivas de eventuais ameaças derivadas da "crise política nacional".

Por fim, entende-se que o presente estudo conseguiu prospectar cenários para o intervalo temporal de 2018-2022, bem como efetuar sua comparação com o levantamento anterior (2014-2018), atendendo ao seu objetivo principal.

A prospeç̧ão de cenários futuros, com a identificação de possíveis pontos de rupturas do ambiente de negócios do ensino superior local, bem como de prováveis oportunidades, permitiu fornecer subsídios para o planejamento estratégico da IES, objeto do presente estudo, além de oferecer parâmetros às demais instituições locais e nacionais.

\section{Referências}

Almeida, F. C., Onusic, L. M., \& Machado Neto, A. J. (outubro, 2005) Proposições e experimentos sobre o método de análise de cenários no varejo brasileiro. Anais do Consejo Latinoamericano de Escuelas de Administration -CLADEA. Santiago, Chile, 5.

Blanning, R. W., \& Reining, B. A. (1998) Building Scenários for Hong Kong Using EMS. Long Rang Planning, 31(6), 900-910. https://doi.org/10.1016/S0024-6301(98)80027-7

Brasil, Republica Federativa do (1996a). Lei $n^{o}$. 10861 de 20 de dezembro de 1996. Recuperado de http://www.planalto.gov.br/ccivil_03/leis/19394.htm.

Brasil, Republica Federativa do (1996b). Lei $n^{\circ}$. 9394 de 20 de dezembro de 1996. Recuperado de http://www.planalto.gov.br/ccivil_03/leis/19394.htm. 
Duarte, T. (2009) A possibilidade da investigação a 3: reflexões sobre triangulação (metodológica). CIES e-Working Papers n. 60, Centro de Investigações e Estudos em Sociologia, Lisboa, Portugal. Recuperado de http://www.cies.iscte.pt/destaques/documents/CIES-WP60_Duarte_003.pdf.

Dutra, T. N. A., \& Carvalho, A. V. (2006) Profissional da informação e as habilidades exigidas pelo mercado de trabalho. Encontros Bibli: Revista Eletrônica de biblioteconomia e Ciências da Informação, Universidade Federal de Santa Catarina, 22, 174-194. Recuperado de http://redalyc.uaemex.mx/redalyc/pdf/147/14702213.pdf.

Kotler, P., \& Caslione, J. A. (2009) Vencer no caos. Rio de Janeiro, Elsevier.

Gremaud, A. P., Vasconcellos, M. A. S, \& Toneto Júnior, R. (2007) Economia Brasileira Contemporânea. Ribeirão Preto: Atlas.

Lastres, H. M. M., \& Albagli, S. (1999) Informação e globalização na era do conhecimento. Rio de Janeiro: Campos.

Mancuso, W. P., \& Oliveira, A. J. (2006) Abertura econômica, empresariado e política: os planos doméstico e internacional. Lua Nova [online], 69, 147 172. https://doi.org/10.1590/S0102-64452006000400007

Marcial, E. C., \& Grumbach, R. J. S. (2002) Cenários prospectivos: como construir um futuro melhor. Rio de Janeiro: Editora FGV.

Oliveira, S. F. P., Machado Neto, A. J., Fadel, B., Durigan, R. H. A., Nogueira, A. T., \& Campanhol, (2011) E. M. Livro dos 60 anos: tessituras de razão e emoção. São Paulo: Uni-FACEF.

Pinto, M. J. A. (2011) Investimentos diretos estrangeiros no setor sucroenergético (Dissertação de Mestrado). Faculdade de Economia, Administração e Contabilidade, Universidade de São Paulo, Ribeirão Preto, SP, Brasil.

Porter, M. E. (2004) Estratégia competitiva: técnicas para análise da indústria e da concorrência. Rio de Janeiro: Elsevier.

Porter, M. E. (1989) Vantagem competitiva: Criando e sustentando um desempenho superior. Rio de Janeiro: Campus.

Ratter, H. (1979) Estudos do futuro: introdução à antecipação tecnológica. São Paulo: FGV.

Schwartz, P. (2006) A arte da visão de longo prazo: planejando o futuro em um mundo de incertezas. Rio de Janeiro: BestSeller. 
Schwartz, P. (2003). Cenários: as surpresas inevitáveis. Rio de Janeiro: Campus.

Silva, W. R., \& Machado Neto, A. J. M. (maio, 2015). Elaboração de cenários prospectivos como fomento às estratégias organizacionais no Ensino Superior. Anais do Congresso do Instituto Franco Brasileiro de Administração de Empresas - IFBAE. Porto Alegre, RS, Brasil, 8.

Silva, W. R. (2013) Um modelo de cenários prospectivos para o setor de prestação de serviços no ensino superior: o caso do Uni-FACEF (Dissertação de Mestrado). Centro Universitário de Franca - Uni-FACEF, Franca, SP, Brasil.

Silveira, R. M. C. F., \& Bazzo, W. A. (novembro, 2006). Transformando a relação do ser humano com o mundo. Anais Simpósio Internacional de Processo Civilizados: tecnologia e civilização. Ponta Grossa, PR, Brasil, 9.

Strebel, P. (1993). Breakpoints: como as empresas exploram mudanças radicais nos negócios. São Paulo: Atlas.

Toaldo, A. M. M. (2006). Formação da estratégia de marketing: aplicação teórica na gestão de instituições educativas. R. Penna, A. M. M. Toaldo, \& S. Sabedot (orgs.). Conhecimento, sustentabilidade e desenvolvimento regional (pp. 43-58). Canoas: Unilasalle. 